\title{
ASPECTOS REGULATÓRIOS DO SETOR ELÉTRICO E OS IMPACTOS DECORRENTES DA IMPLANTAÇÃO DE LINHAS DE TRANSMISSÃO
}

\section{REGULATORY ASPECTS OF ELECTRICITY SECTOR AND IMPACTS ARISING FROM IMPLANTATION OF THE TRANSMISSION LINES}

Daniel Augusto Ribeiro ${ }^{1}$

\section{RESUMO}

A transmissão de energia elétrica, embora essencial ao desenvolvimento energético, requer a analise dos aspectos regulatórios e dos impactos resultantes de sua implantação além de quais os mecanismos de mitigação destes efeitos. São intervenções necessárias para instalar estruturas e equipamentos afim de possibilitar a prestação do serviço público de transmissão e distribuição de energia elétrica, impondo limitações no uso das propriedades e impactos ambientais diversos. Conclui-se, com este estudo, que devido à grande extensão do território brasileiro, não se verifica um planejamento que minimize as interferências das linhas de transmissão na propriedade agrária, embora existem tais mecanismos.

Palavras-chave: Linhas de transmissão, Energia elétrica, Regulação do setor elétrico

\begin{abstract}
The transmission of electricity, while essential to energy development, requires the analysis of the regulatory aspects and impacts resulting from its implementation beyond which mitigation mechanisms of these effects. Interventions are required to install structures and equipment in order to enable the delivery of public service transmission and distribution of electricity, imposing restrictions on the use of the properties and various environmental impacts. It is concluded from this study that because of the large size of Brazil, there is not a plan that minimizes the interference of the transmission lines on land ownership, although there are such mechanisms.
\end{abstract}

Keywords: Transmission lines, Electricity, Regulation of the electricity sector

\footnotetext{
${ }^{1}$ Mestre em Direito Agrário pela Universidade Federal de Goiás, UFG - Goiás, GO, Brasil.

E-mail: indexlaw.ojs@ hotmail.com
} 


\section{INTRODUÇÃO}

O desenvolvimento da humanidade tem sido possível graças à organização social e à existência de insumos como transportes, comunicações, abastecimento alimentar. A eletricidade apresenta-se, neste contexto, com essencial ao funcionamento do aparato tecnológico, inclusive para produção e distribuição de alimentos. Sem dúvida, o crescimento econômico e da qualidade de vida, tanto para as gerações presentes quanto futuras, depende da energia elétrica, produzida nas suas mais diversas formas, dentro de um modelo de desenvolvimento sustentável.

A energia elétrica, objeto do Direito de Energia, é considerada como bem essencial para indústrias, comércios, residências, em incontáveis formas de utilização. Para tanto, seu fornecimento requer requisitos mínimos a serem observados, como a regularidade, continuidade e eficiência na sua prestação, associado à modicidade das tarifas.

Para o alcance da modicidade das tarifas, no que se refere ao fornecimento do serviço público de energia elétrica, requer eficiência e otimização das instalações. A implantação de linhas de transmissão de energia elétrica, responsável pelo transporte entre as fontes geradores e consumidores, requer passagem em imóveis, intervenções ambientais e efeitos diversos.

Diante disso, tem-se o seguinte problema jurídico: quais impactos provocados resultantes da implantação de linhas de transmissão de energia elétrica e quais os mecanismos de mitigação destes efeitos?

Com o objetivo geral de compreender os aspectos regulatórios de mensuração e mitigação dos impactos decorrentes da implantação de linhas de transmissão de energia elétrica, tem-se como objetivos específicos: (a) analisar os conceitos e princípios do direito de energia envolvendo as linhas de transmissão, os aspectos construtivos que provocam limitações ao direito de propriedade e demais efeitos decorrentes; (b) investigar os aspectos econômicos e indenizatórios quando da intervenção, impactos ambientais e características construtivas que possa mitigar os efeitos resultantes da implantação de linhas de transmissão.

A metodologia de abordagem responsável pelo raciocínio utilizado no desenvolvimento da pesquisa foi o indutivo, partindo dos pontos particulares postos para uma questão mais ampla e geral (generalização). Como técnica metodológica, adotou-se a pesquisa teórica e estudos de caso, mediante coleta e análise de documentos, legislação e jurisprudências.

Considerando que o bem 'energia elétrica' é essencial e estratégico, se analisará como se dá Política Energética no Brasil, cuja gestão, organicidade e planejamento devem 
alcançar as necessidades atuais e futuras. Serão analisados ainda o arcabouço normativo e feitas considerações da energia elétrica como serviço publico, a fim de compreender, também, o papel do Estado em realiza-lo.

Além do aspecto econômico, serão feitas abordagens quanto à necessidade de segurança energética para se assegurar desenvolvimento social à qualidade de vida. Serão também objeto de estudo as entidades responsáveis por gerir o sistema elétrico brasileiro e realizar o planejamento do sistema.

O papel da infraestrutura necessária para sua produção e distribuição da energia, nesse plano, se mostra relevante para atendimento dos mercados consumidores. Neste ponto, deverá se verificar a conciliação entre os investimentos necessários com a viabilidade econômica de sua implementação, buscando sua forma mais eficiente, tanto do ponto de vista econômico e quanto socioambiental.

Serão também avaliados os aspectos ambientais e medidas de mitigação na implantação das linhas de transmissão, levando em consideração um processo sustentável de desenvolvimento, de forma a serem considerados nos empreendimentos características como localização, vocação regional e tecnologia a ser utilizada.

\section{Energia Elétrica: Conceito e Regulação}

Em um mundo cada vez mais tecnológico e industrializado, a prestação do serviço público de fornecimento de energia elétrica, continuamente e com qualidade, torna-se cada vez mais indispensável. O parque fabril, comércios e residências necessitam do suprimento de energia para as atividades mais básicas de cada um desses seguimentos.

Nesse sentido, faz-se necessária a compreensão desse bem denominado energia elétrica, o caráter público de seu fornecimento e como, no plano normativo, está organizada a Política Energética Brasileira. Será de posse dessas as premissas que se permitirá compreender a estruturação do fornecimento de energia por meio de linhas de transmissão, discorrendo sobre a regulação deste setor e seus efeitos ambientais, estruturais e impactos associados.

\subsection{Energia Elétrica: bem, serviço e função social}

A energia elétrica pode ser considerada um dos bens essenciais de destaque que marcaram o desenvolvimento da humanidade. Desde os primórdios com a utilização do fogo, 
passando pelas máquinas de vapor que assinalaram o surgimento da indústria, a utilização de combustíveis fósseis, a energia elétrica e nuclear, são diversas as formas de energia manejadas pelo homem que impulsionaram e impulsionam o desenvolvimento.

Energia pode ser definida, conforme Glossário de Ecologia e Ciências Ambientais, como uma força capaz de desenvolver trabalho, podendo existir sob diversas formas, como luz, calor, eletricidade, energia química armazenada nas ligações químicas dos combustíveis fósseis (petróleo, carvão mineral), açúcar, armazenamento em Trifosfato de Adenosina - ATP - e inúmeros outros compostos e também sobre a forma de energia nuclear emitida dos radioisótopos.

E como bem, a energia elétrica é dotada de mensuração econômica, visto os dispêndios para sua produção e distribuição. O Código Civil de 2002 estabeleceu no artigo 83, inciso I, que consideram-se móveis para os efeitos legais as energias que tenham valor econômico. No mesmo sentido, o Código Penal ao tipificar o crime de furto, no artigo 155, parágrafo $3^{\circ}$, fez consistir que se considera crime subtrair, para si ou para outrem, coisa alheia móvel, equiparando à coisa móvel a energia elétrica ou qualquer outra que tenha valor econômico.

A legislação buscou conferir à energia elétrica, que possui valor econômico, proteção de forma a assegurar sua proteção enquanto recurso a ser utilizado de forma individual pelos usuários.

No plano coletivo, o tema energia tem provocado debates políticos e científicos em diversos setores da sociedade. Isso porque nas discussões estão envolvidas controvérsias ambientais, sociais, econômicas, aspectos geopolíticos, questões tecnológicas, institucionais, enfim, são acionadas diversas instâncias e instituições para opinarem, ou mesmo decidirem, sobre o assunto.

Ressalta-se a função social da eletricidade, que compõe um dos pré-requisitos mínimos necessários e indispensáveis para as atividades sociais e econômicas. Não ter acesso à eletricidade, implica em exclusão social, cultural e digital, sendo mais nociva para os mais necessitados, visto estarem relacionados pobreza e o não acesso à eletricidade.

Os serviços de energia, por serem essenciais, requerem que sejam promovidas soluções adequadas, dado os impactos sociais e políticos, representando um desafio, de acordo com a política de desenvolvimento adotada . Dessa forma, as políticas públicas que

\footnotetext{
${ }^{1}$ GRISI, Breno Machado. Glossário de Ecologia e Ciências Ambientais. $3^{\text {a }}$ ed. rev. e ampl. João Pessoa, 2007. Disponível em <http://www.em.ufop.br/ceamb/petamb/cariboost_files/glossario_20de_20ecologia_20e_ 20ciencias_20ambientais.pdf $>$. Acesso em 09-jan-2016.
} 
envolvam o fornecimento de energia elétrica promover a segurança energética, e por conseguinte, a segurança econômica.

O Sistema Elétrico Brasileiro encontrar-se no limite de sua capacidade de utilização como veículo de implementação de políticas pelo Estado, que como ressalta Figueiredo, que na sua origem visa minimizar/reduzir as desigualdades regionais e à inclusão social e digital, mas no entanto, evidencia-se a ausência de políticas integradas que atendam às aspirações da população em geral, sejam ou não consumidores de energia. ${ }^{2}$

Segundo Maria João, a utilização e à repercussão econômica da eletricidade pressupõe a sua importância como fator primordial para o desenvolvimento humano e para o desenvolvimento econômico, como variável estratégia decorrente de processo detentor de tecnologia, como fator de progresso, sinergia em se representa o sangue da sociedade. A importância da eletricidade não se encerra na possibilidade de tornar a vida das pessoas melhor, pois possibilita ao homem o desenvolvimento de sua condição humana primordial, a inteligência é o raciocínio, liberando-o de trabalhos penosos. 3

Indiretamente, a eletricidade beneficia como uma variável econômica para possibilitar o desenvolvimento das nações. A sociedade moderna é dependente do fornecimento de energia elétrica e, por consequência, a falta de acesso a esta por parte da população gera exclusão social a diminuição da qualidade de vida.

Por essa razão o direito de acesso ao fornecimento de energia elétrica deve direcionar o planejamento do setor elétrico, visto que a eletricidade é um recurso econômico estratégico para o progresso e desenvolvimento do país.

\subsection{Política Energética Brasileira}

Conforme Adriano Pires Rodrigues e Danilo de Souza Dias, os grandes alicerces da proposta de Política Energética para o Brasil consistem na adequação institucional e legal do arcabouço governamental, ou seja, o redirecionamento do papel do Estado Brasileiro, políticas públicas integradas, comprometidas e convergentes com a construção da

\footnotetext{
2 FIQUEIREDO, Job de. A utilização do setor elétrico como instrumento de implementação de políticas públicas. Rio de Janeiro, $2006 \quad$ Disponível $\quad$ em: <http://www.nuca.ie.ufrj.br/gesel/eventos/seminariointernacional/2006/artigos/pdf/Job_Figueiredo.pdf >. Acesso em: 22.jan.2015, p. 9.

${ }^{3}$ MEDEIROS, Edmundo Emerson de Infraestrutura energética : planejamento e regulação do setor elétrico. São Paulo : MP Ed., 2009, p. 33 e 34.
} 
infraestrutura necessária ao crescimento do país e fortalecimento, integração e independência das agências reguladoras. 4

Para Luiz Gustavo Kaercher Loureiro, a política energética configura um conjunto que extrapola as preocupações setoriais e as coloca em um horizonte mais amplo, ou seja, a política energética articula o uso das diferentes fontes e as diferentes indústrias energéticas à vista de certos objetivos, considerando certas condicionantes materiais. ${ }^{5}$

Os objetivos de toda política energética é a suficiência energética sustentável (energia em quantidade, qualidade e preços capazes de atender às necessidades nacionais, atuais e futuras) ${ }^{6}$. Trata-se aqui de um dado não jurídico, mas que deve ingressar no direito, na forma de norma, em processo complexo e não isento de tensões e dificuldades, compondose e articulando-se com outros fins e objetivos. ${ }^{7}$

No marco regulatório atual, conforme expõe Luiz Gustavo Kaercher Loureiro, e composto por várias Leis, Decretos, Atos Administrativos Normativos, pouco articulados entre si, que também acabam convivendo com os modelos setoriais anteriores. Tais modelos abordam, parcial e fragmentada, capítulos da indústria elétrica, possuindo, por conseguinte, pouca organicidade interna e quase nenhuma externa, o que dificulta a percepção ou desenvolvimento de uma política energética brasileira. ${ }^{8}$

No que diz respeito à indústria elétrica, a Constituição atribuiu à União as competências material, legislativa e de outorga ${ }^{9}$. No seu art. 22 , IV, a categoria genérica energia, outorgando à União competência para legislar sobre águas e energia, e a possibilidade da participação da iniciativa privada no desenvolvimento dessas atividades consta nos dispositivos do art. 21 , XII, b, art. 176, art. 117, $\S 1^{\circ}$, art. $25, \S 2^{\circ}$, art. 21, XXIII, b e c. A letra b, do inc. XII, do art. 21, cuidou das atividades ligadas à produção e ao oferecimento de energia.

A Lei $n^{\circ} 8.987 / 1995$ regulou o regime de concessão e permissão da prestação de serviços públicos, em conformidade estabelecido no Art. 175, da Constituição, disciplinou os

\footnotetext{
${ }^{4}$ PIRES, Adriano; FERNÁNDEZ, Eloi Fernández y; BUENO, Júlio Cesar Carmo (org.). Política energética para o Brasil: propostas para o crescimento sustentável. Nova Fronteira: Rio de Janeiro, 2006, p. 69.

5 LOUREIRO, Luiz Gustavo Kaercher. Constituição, energia e setor elétrico. Porto Alegre: Fabris, 2009, p. 34.

${ }^{6}$ PIRES, Adriano; FERNÁNDEZ, Eloi Fernández y; BUENO, Júlio Cesar Carmo (org.). Política energética para o Brasil: propostas para o crescimento sustentável. Nova Fronteira: Rio de Janeiro, 2006, p. 43-44

7 LOUREIRO, op. cit., p. 53.

${ }^{8}$ LOUREIRO, Luiz Gustavo Kaercher. Algumas reflexões sobre a base normativa do setor elétrico brasileiro. Rio de Janeiro: IFE, 2007.

${ }^{9}$ LOUREIRO, Luiz Gustavo Kaercher. O regime jurídico da energia elétrica nas Constituições brasileiras - as premissas. In: REIS, Jorge Renato dos; LEAL, Rogério Gesta (Org.). Direitos sociais e políticas públicas: desafios contemporâneos. Santa Cruz do Sul: EDUNISC, 2008. Tomo 8, p. 25.
} 
direitos e deveres dos usuários, das empresas prestadoras desses serviços, as condições da licitação para outorga, as cláusulas essenciais do contrato de concessão, os encargos da concessionária, as possibilidades de intervenção e as formas de extinção da concessão.

Segundo determinação do Art. $6^{\circ}$ da referida norma, toda concessão ou permissão pressupõe a prestação de serviço adequado ao pleno atendimento dos usuários, considerado serviço adequado é o que satisfaz as condições de regularidade, continuidade, eficiência, segurança, atualidade, generalidade, cortesia na sua prestação e modicidade das tarifas.

O Art. $7^{\circ}$ por seu turno disciplina os direitos e deveres dos usuários, assegurando-lhes receber o serviço adequado como as informações para defesa dos seus interesses, liberdade de escolha, quando for o caso, e de contribuir para a permanências das boas condições dos bens públicos através dos quais lhes são prestados os serviços.

A Lei $n^{\circ} 9.478 / 1997$, ao dispor sobre os princípios e objetivos da política energética nacional, destacou no caput do Art. $1^{\circ}$ o aproveitamento racional das fontes de energia. Já a Lei de Greve, Lei $n^{\circ}$ 7.783/1989, designou como serviços essenciais, independentemente de serem públicos ou de utilidade pública, incluindo no rol a produção e distribuição de energia.

A Lei 8.987/1995 que definiu o regime de concessão e permissão da prestação de serviços públicos por empresas privadas, permitiu que tais serviços pudessem ser concedidos às empresas privadas vencedoras de processo licitatório.

Com a Lei 9.074/1995, que definiu normas para outorga e prorrogação das concessões e permissões de serviços públicos. Esta Lei apresentou em seu capítulo II as especificidades relacionadas aos serviços de energia elétrica, definindo que empreendimentos de transmissão de energia elétrica deveriam ter prazos de concessões necessários à amortização dos investimentos limitados em 30 anos de concessão, podendo ser prorrogados por igual período.

As Leis 10.847 e 10.848 e o Decreto 5.163, todos de 2004, alteraram o setor elétrico brasileiro incluindo no modelo as concessões a partir da licitação de novos empreendimentos de geração e transmissão de energia elétrica, bem como a determinação do livre acesso aos sistemas de transmissão e distribuição e a liberdade para os grandes consumidores escolherem seus supridores de energia.

Neste contexto, dentre as entidades que compõem o setor elétrico brasileiro, estão o Ministério de Minas e Energia (MME), Agência Nacional de Energia Elétrica (ANEEL), Empresa de Pesquisa Energética (EPE) e Operador Nacional do Sistema Elétrico (ONS).

O MME, criado pela Lei 3.782/1960 e extinto em 1990, voltando a ser criado pela Lei 8.422/1992, tem como competências no planejamento de desenvolvimento das áreas de 
geologia, recursos minerais e energéticos; aproveitamento da energia hidráulica; mineração e metalurgia; petróleo, combustível e energia elétrica, incluindo a nuclear.

A ANEEL, criada pela Lei 9.427/1996, cujas atribuições, vinculada ao MME, são regular e fiscalizar os agentes do setor de energia elétrica. A EPE criada pela Lei 10.847/2004, também vinculada ao MME, tem como objetivo prestar serviços na área de estudos e pesquisas destinadas a subsidiar o planejamento do setor energético..

O ONS, criado pela Lei 9.648/1998, é uma empresa privada, sob regulação e fiscalização da ANEEL, responsável pela coordenação e controle da operação das instalações de geração e transmissão de energia elétrica no Sistema Interligado Nacional (SIN).

Considerando que no Sistema Elétrico Brasileiro a base geradora de energia elétrica tem a característica de ser eminentemente hidráulica, e a que as bacias hidrográficas são distantes entre si e localizadas em regiões com diferentes regimes de chuvas, faz com que a produção da energia requeira operação coordenada das usinas hidroelétricas (despacho de geração) objetivando a otimização da utilização eletroenergética do parque gerador instalado.

Os sistemas de transmissão no Brasil são, em sua maior parte, interligados, compondo o Sistema Interligado Nacional (SIN) que é constituído pelas instalações responsáveis pelo suprimento de energia elétrica a todas as regiões do país, interligadas eletricamente.

Este sistema compreende um sistema hidrotérmico de grande porte, com forte predominância de usinas hidrelétricas, geralmente localizadas longe dos centros de carga, e por uma extensa malha de transmissão que abrange as empresas de todas as regiões do país, possibilitando a transferência de energia dos locais onde é produzida para os centros de consumo.

As atividades do Setor Elétrico Brasileiro - SEB - podem ser agrupadas em quatro segmentos principais: Geração, Transmissão, Distribuição e Comercialização.

O segmento de geração abrange todas as atividades de produção de energia (usinas hidrelétricas, termelétricas e outras fontes alternativas), incluindo a importação de países de fronteira. Devido ao grande potencial hidráulico do Brasil e a eficiência da conversão, a forma de produção de energia mais empregada é a gerada por hidrelétricas.

O segmento de transmissão engloba as atividades necessárias à transferência da energia produzida até os grandes centros de consumo. A energia elétrica é transportada por 
meio de cabos elétricos, e esses, por sua vez, são apoiados em estruturas metálicas estruturadas sobre sua fundações conhecidas como torre de Linha de Transmissão.

A distribuição encarrega-se da transferência final da energia, a partir dos pontos de entrega na rede de alta tensão até os consumidores finais. O último segmento, a comercialização está encarregada das atividades de contratação da energia gerada e sua revenda aos consumidores.

\section{Setor de Transmissão de Energia Elétrica Brasileiro}

O fornecimento de energia elétrica depende de um vasto e complexa rede e infraestrutura compreendida desde a geração, transmissão à distribuição da energia aos consumidores e usuários finais.

A transmissão de energia elétrica tem por função, em sentido amplo, transmitir blocos de energia das áreas de produção até o entorno das áreas de consumo, onde ocorrem as conexões com a distribuição propriamente dita, a qual se encarrega de encaminhar a energia elétrica aos mais diversos tipos de consumidores, tais como indústrias, comércio em geral, residências, iluminação pública, dentre outros.

Apesar da ausência de um conceito preciso em nosso ordenamento jurídico ou mesmo na literatura, em sentido lato, infraestrutura pode ser definida em linhas gerais, segundo Edmundo Medeiros, como um conjunto de estruturas, equipamentos e instalações que constituem a base sobre a qual é produzida a prestação de serviços considerados essenciais para a vida ou para o desenvolvimento de fins produtivos. 10

Entre os diversos setores de infraestrutura que dão suporte ao desenvolvimento de uma nação, o energético sem sombra de dúvidas ocupa posição estratégica. No caso brasileiro, a energia que movimenta o país tem origem tanto de fontes primárias renováveis, hidráulica, produtos da cana de açúcar, quanto em fontes não renováveis como petróleo, gás natural, urânio, dentre outras.

Substanciais modificações foram introduzidas na estrutura do setor elétrico brasileiro na década de 1990 deram seu contorno percebido nos dias atuais ${ }^{12}$, sendo que a relevância da infraestrutura não se restringe ao atendimento das necessidades primárias de vida da população, que pode ser impactada pelos efeitos econômicos causados pelo 
deficiente provimento de serviços de infraestrutura. Com efeito sem investimentos de infraestrutura, a

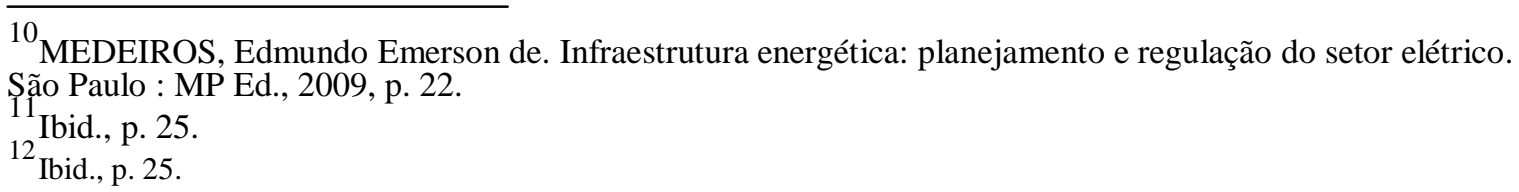

economia de um país não reúne condições para expandir seu mercado interno e consequentemente competir no mercado externo. ${ }^{13}$

O papel das Linhas de Transmissão é assegurar o transporte da energia elétrica, atendendo inclusive o suprimento da demanda futura de energia elétrica na sua forma mais eficiente, tanto do ponto de vista econômico, como, principalmente, ambiental ${ }^{14}$. Com característica predominantemente aéreas, caracterizadas por linearidade e grandes extensões, o que resulta na necessidade de passagem por regiões de diversidade morfológica e com diferentes características de uso e ocupação. Seu projeto requer diferentes soluções, tanto na determinação de seu traçado, quanto na escolha das tecnologias necessárias à sua implementação.

As linhas de transmissão são associadas à transmissão de energia envolvem números grandiosos, tanto pela quantidade de consumidores, como pela quilometragem das malhas, hectares de áreas compreendidas como faixas de passagem e, em muitos casos, a um número significativo de pessoas deixadas sem energia elétrica ao longo de seu traçado.

Segundo o Instituto Brasileiro de Geografia e Estatística - IBGE, no Censo 2010, em 2010 havia 1,3\% de domicílios sem energia elétrica, com maior incidência nas áreas rurais do País $(7,4 \%)$. A situação extrema era a da região Norte, onde $24,1 \%$ dos domicílios rurais não possuíam energia elétrica, seguida das áreas rurais do Nordeste $(7,4 \%)$ e do Centro-Oeste $(6,8 \%)$. $^{15}$

Para os critérios técnicos de engenharia, o estudo da diretriz da linha de transmissão e de localização, considera-se os fatores ambientais, visando à minimização das interferências com os meios físico, biótico e meio socioeconômico, e a consequente minimização ou eliminação dos potenciais impactos ambientais decorrentes da implantação dos empreendimentos. 
O projeto econômico de qualquer rede elétrica para transmitir energia, passa pela escolha dos níveis de tensão e, consequentemente, de corrente, mais adequados e pela determinação dos cabos condutores, torres, subestações e equipamentos de compensação reativa, dentre os principais aspectos influentes, de modo a minimizar o custo total, o qual é formado pelos custos dos investimentos e os custos das perdas capitalizados durante a vida

\footnotetext{
${ }^{13}$ Ibid., p.28.

14 SAMEK, et al. A opção pela Hidrelétrica. Estado de São Paulo. 2007. Disponível em: $<$ http://www.estado.com.br/editoras>. Acesso em 16-jun-2014.

${ }^{15}$ BRASIL. Instituto Brasileiro de Geografia e Estatística - IBGE. Censo Demográfico 2010. Disponível em

http://biblioteca.ibge.gov.br/visualizacao/periodicos/93/cd_2010_caracteristicas_populacao_domicilios.pdf> . Acesso em 13-out-2014.
}

útil da instalação. Maiores níveis de tensão e maiores bitolas correspondem a maiores investimentos e menores perdas Joule.

No Brasil, para assegurar maior confiabilidade e diminuir volumes de investimento, o sistema de transmissão é interligado, o que permite maior liberdade operativa quanto ao uso das diversas fontes geradoras hidrelétricas, e a busca da melhor utilização da água, o que é feito pelo Operador Nacional do Sistema Elétrico - ONS.

Para a implantação da linha de transmissão, a extinção de determinadas culturas agrícolas e benfeitorias decorrentes são compensados financeiramente a partir da utilização de metodologia instituída pela NBR 14.653-3, define metodologia para mensurar, a partir de diversas variáveis, o valor de benfeitorias rurais, conforme recomendação do Instituto Brasileiro de Avaliações e Perícias de Engenharia- IBAPE.

Algumas benfeitorias rurais e plantios agroflorestais não podem coexistir com a linha de transmissão, a exemplo de silvicultura de espécies arbóreas de rápido crescimento.

Conforme estudo efetuado na Tese de Doutoramento de Ricardo Abranches Felix Cardoso Jr., o autor verificou que para a empreendimentos lineares, observa-se que o órgão ambiental licenciador vem ativamente participando do processo decisório dos traçados, exigindo que alternativas de variantes sejam implementadas em áreas ambientais sensíveis, de forma a reduzir os impactos ambientais que afetam a sociedade. ${ }^{16}$

Segundo o autor, para que um traçado seja considerado otimizado ele deve garantir que as variáveis ambientais sejam devidamente incorporadas ao projeto de 
engenharia, utilizando-se para isso as melhores práticas construtivas, dentro de uma economicidade estabelecida, de forma a proporcionar a maior linearidade possível entre as subestações.

Dentre as restrições técnicas e ambientais do traçado, destacam-se as comunidades Tradicionais (Terras Indígenas, Comunidade Quilombolas e Assentamentos Fundiários); as Unidades de Conservação (Lei 9985/00); as interferências em Áreas de Preservação Permanente: com o novo código florestal brasileiro (Lei 12.651/12); interferências em fragmentos florestais com mata nativa; e benfeitorias rurais, dentre outros. Trata-se de uma conscientização sobre a importância do meio ambiente e sobre a necessidade de sua preservação, que tem ganhando espaços em todos os setores da sociedade.

As atividades relacionadas à energia são responsáveis por uma grande parte dos danos ao meio ambiente e, em função disso, a consideração dos impactos ambientais passou a

\footnotetext{
${ }^{16}$ CARDOSO JR., Ricardo Abranches Felix Licenciamento Ambiental de sistemas de transmissão de energia elétrica no Brasil: Estudo de caso do sistema de transmissão do Madeira/ Ricardo Abranches Felix Cardoso Junior - Rio de Janeiro: UFRJ / COPPE / Programa de Planejamento Energético, 2014.
}

exercer considerável influência no planejamento da produção, transmissão, distribuição e utilização dos energéticos, valorizando o uso de energias renováveis e estimulando a eficiência energética e a busca da minimização dos impactos ambientais dos empreendimentos elétricos. 17

O conceito de impacto ambiental foi dado pela Resolução do Conselho Nacional do Meio Ambiente - CONAMA - N. 001/86, em que se evidencia aspectos ambientais e econômicos.

Para a implantação de Linhas de Transmissão são necessárias intervenções nos imóveis, que passarão a ter restrições no seu uso e gozo, afim de garantir segurança às instalações elétricas. Para tanto, a legislação e os atos regulatórios infraconstitucionais estabelecem definições próprias.

O Decreto N. ${ }^{\circ} 35.851 / 1954$ estabelece as concessões para o aproveitamento industrial das quedas d'água, ou, de produção, transmissão e distribuição de energia elétrica, conferem aos seus titulares o direito de constituir as servidões administrativas 
permanentes ou temporárias, exigidas para o estabelecimento das respectivas linhas de transmissão e de distribuição.

A norma ABNT NBR 5.422 dispõe sobre projeto de linhas aéreas de transmissão de energia elétrica, para as faixas de segurança sob as torres e ao longo das redes das LT.

A legislação brasileira que regula o uso e a ocupação do solo define que a função da faixa de servidão é preservar as áreas próximas às torres que suportam os cabos de eletricidade, e um corredor limitado por linhas paralelas às LT. Essa área é chamada de faixa de segurança. A largura da faixa de segurança varia de acordo com a tensão transmitida pelas linhas.

Conforme a NBR-5.422/85, Faixa de segurança em LT é a largura da faixa de segurança de uma LT de energia elétrica deve ser determinada levando-se em conta o balanço dos cabos devido à ação do vento, efeitos elétricos e posicionamento das fundações de suportes e estais.

Os órgãos reguladores e de fiscalização de energia elétrica do Brasil não informam uma definição especifica as diversas faixas, tensões (volts) e dimensões das mesmas uma vez que estas variam de região para região, tendo em vista a topografia, vegetação, tipo de solo

\footnotetext{
17 SANTOS, R. H. O Planejamento Integrado de Recursos e a Regulação: a experiência dos EUA e as perspectivas no Brasil. UPUSP/IEE, São Paulo, 1997. Dissertação (Mestrado) - Escola Politécnica, Universidade de São Paulo.
}

entre outros que demandam projetos e formas diferentes a serem aplicadas para as Linhas de Transmissão.

A faixa de segurança é calculada na fase de projeto, observando diversos parâmetros, entre os quais a tensão da linha, velocidade do vento no local e pode variar de acordo com essas condições.

Os distanciamentos das estruturas e também dos cabos de Linhas de Transmissão de sacadas das edificações, árvores, outras estruturas de LT, taludes, transposição de estradas, tráfegos pluviais, Linhas férreas, estruturas metálicas e outros obstáculos devem obedecer a critérios calculados levando em conta os valores das tensões da rede e também da altura das estruturas. Fato este que irá garantir o bom desempenha o sistema e sobretudo a segurança das pessoas porventura envolvidas neste sistema. 
Dentro da faixa de servidão e segurança não são permitidas benfeitorias ou atividades que propiciem a permanência ou aglomeração constante ou eventual de pessoas ou aquelas que coloquem em risco a operação da linha de transmissão.

A partir dessas primeiras impressões e conceitos, deve-se compreender os instrumentos para tratamento da questão ambiental de demais mecanismos de mitigação dos efeitos da implantação de linhas de transmissão no contexto brasileiro, referenciandose às atividades energéticas e às práticas internacionais, quando necessário.

\section{Aspectos Sócio-Ambientais na Implantação de LTs}

Os empreendimentos de energia elétrica, em regra, são obras de grande porte e demandam investimentos em relevantes. A política energética deve buscar, por um lado, o atendimento das demandas crescentes de usuários que querem receber o suprimento de energia elétrica, e por outro, fomentar a modicidade das tarifas, ou seja, ter-se uma menor oneração a estes usuários. Diante dessa perspectiva, que se propõe a analise dos aspectos econômicos e indenizatórios decorrentes da intervenção de tais empreendimentos.

Em um processo sustentável de desenvolvimento, devem ser considerados de forma abrangente os fatores que de algum modo interferem no meio em que há a intervenção, incluindo os aspectos ambientais. No caso das Linhas de Transmissão, além da tecnologia a ser adotada, leva-se em consideração ainda a localização do empreendimento, vocação regional, verificação dos impactos nos diversos aspectos do meio ambiente.

O Setor Elétrico possui alto potencial de geração de impactos sociais e ambientais, como é caso, seja na geração, transmissão e distribuição de energia elétrica. Através dos

instrumentos de avaliação ambiental, busca-se identificar e mensurar os impactos gerados pelas atividades passíveis de avaliação.

No contexto global das questões ambientais e sociais associadas à uma linha de transmissão, muitos dos impactos poderiam ser triviais ou sem significância para uma decisão a ser tomada. Na prática, a decisão irá girar em torno de um pequeno conjunto de questões de menor relevância. 
Os responsáveis pela tomada de decisão, a população local e a comunidade científica, possuem um interesse especial no auxílio do delineamento das questões ou problemas a serem considerados, de forma que o desígnio do escopo permite o exame e debate de seus respectivos pontos de vista. Assim, um ponto de partida para a avaliação dos impactos pode ser a catalogação dos mesmos.

A análise dos principais impactos socioambientais associados às linhas de transmissão e às subestações, embora abrangente, é importante para a definição de programas socioambientais e escolha dos métodos de valoração ambiental.

Os impactos socioambientais associados às linhas de transmissão podem ocorrer nas diferentes fases do empreendimento, conforme detalhadas anteriormente, desde a instalação até a desativação. É interessante lembrar que, dentre os empreendimentos ligados ao setor elétrico, as linhas de transmissão podem ser consideradas como empreendimentos que provocam os menores impactos negativos sobre o meio ambiente.

No entanto, em função do sistema de remuneração imposto ao sistema de transmissão no atual modelo do setor elétrico, torna-se de extrema importância a identificação de todos os custos incorridos nos empreendimentos, principalmente aqueles associados às questões socioambientais. Daí a necessidade de uma caracterização completa dos impactos ambientais potenciais.

Especial atenção é dada aos impactos sobre o meio socioeconômico em virtude do seu potencial em gerar externalidades como as relacionadas ao uso do solo, ruídos e efeitos elétricos e visuais.

O Relatório Ambiental Preliminar - RAP - é o primeiro documento a ser apresentado para o Licenciamento Ambiental. Sua função é instrumentalizar a decisão de exigência do Estudo de Impacto Ambiental - EIA, para obtenção de Licença Prévia, ou de avaliar o empreendimento quando este for dispensado do EIA. Em caso de exigência, juntamente com outros instrumentos subsidiará a definição do Termo de Referência para o EIA. Quando ocorre a dispensa do EIA a avaliação do empreendimento é feita baseada no conteúdo do RAP, adicionado a outros elementos.

A ELETROBRÁS desenvolveu um estudo de avaliação de passivos ambientais em que relacionada os aspectos que devem ser considerados para a implantação de linhas de transmissão e respectivas ações de mitigação, dentre os quais se destacam ${ }^{18}$ : 
a) Abertura da faixa de servidão da linha, de estradas de acesso, de praças de montagem de estruturas, de áreas de lançamento de cabos e de áreas para canteiro de obras: retirada da cobertura vegetal; erosão do solo; interferência com recursos hídricos; interferência na fauna; efeito de borda; interferência em unidades de conservação; invasão de espécies exóticas; fragmentação dos habitats; maior acesso às áreas silvestres ou de relevante interesse ambiental; interferência com populações indígenas ou outros grupos étnicos; desapropriação de terras; limitação ao uso do solo devido a servidão; criação de expectativa na população afetada; deslocamento da população; afetada; indução à ocupação desordenada das margens de LTs e estradas de acesso; interferência nas atividades agropecuárias; interferência em edificações, vias públicas e no tráfego; interferência em locais de; interesse histórico e cultural.

b) Montagem de estruturas e praças de lançamento de cabos: danos temporários ao solo; danos temporários à vegetação; danos temporários às áreas cultivadas; interferência com população indígena e outros grupos étnicos.

c) Manutenção da faixa de passagem das linhas (uso de herbicidas, etc.): interferência na fauna e na flora; contaminação do solo, águas superficiais e do lençol freático.

d) Inclusão de obstáculo artificial: interferência na rota de migração de fauna terrestre e alada; risco para aviação; degradação da paisagem, desordem cênica e falta de integração visual.

e) Energização e operação da linha, surgimento de efeitos eletromagnéticos: efeitos biológicos na fauna e na flora; Efeitos biológicos no homem; Efeitos devidos à transferência de potencial; Interferência em rádio e TV e ruído audível.

\section{Alternativas Construtivas das Linhas de Transmissão para Mitigação dos seus Efeitos}

Destaca-se dentre as atribuições do Poder Público, na gestão da implantação das Linhas de Transmissão, seu dever de provocar a menor intervenção aos particulares, gestão da segurança do sistema elétrico e permitir o aproveitamento racional das áreas afetadas.

\footnotetext{
${ }^{18}$ ELETROBRÁS. DEA. Avaliação de passivos ambientais: roteiros técnicos / Centrais Elétricas Brasileiras S.A., DEA; coordenado por Fani Baratz. - Rio de Janeiro : Eletrobrás, 2000, p. 44 a 46.
} 
O traçado de uma linha de transmissão pode atinge imóveis agrários destinados à agricultura ou pecuária, ainda que possua um planejamento para que se tenha um trajeto ótimo, pode atingir propriedades cujo solo possua alta fertilidade/produtividade, o que sofreria serias limitações de exploração, diante limitações como as expostas.

Compete às Concessionárias do Serviço Público de Transmissão de Energia Elétrica deve fiscalizar suas instalações para evitar ocorrências como ocupações irregulares sob as LT, atender às normas de segurança vigentes e ainda estabelecer o bom desempenho do sistema elétrico aos seus consumidores.

As ações para conter ocupações e manter a Faixa de Servidão de acordo com as premissas de segurança envolvem principalmente a execução de ações específicas, a exemplo de plantação agrícola de espécies permitidas em caráter comunitário, que consiste no controle de vegetação para evitar acidentes em decorrência de contato com os cabos e campanhas de conscientização contra queimadas.

Sob outro aspectos, as redes de geração, transmissão e distribuição de energia elétrica produzem Campo Eletromagnético de baixa frequência, geralmente compreendendo frequências entre $50 \mathrm{~Hz}$ e $60 \mathrm{~Hz}$, razão pela qual a proximidade de moradias a Faixas de Segurança de LT é estudada cada vez mais na intenção de respostas sobre possíveis patologias à população ou as espécies cultivadas em suas imediações.

São características pra o dimensionamento de um sistema de transmissão a definição dos cabos, potência, tensão e distâncias entre a fonte de geração e o consumo. As torres metálicas de um sistema de transmissão são dimensionadas de forma a suportarem os cabos condutores de energia elétrica e respectivas estruturas de segurança. Os cabos condutores devem ser mantidos a uma distância de segurança mínima do solo e de obstáculos para evitar descargas ou curtos-circuitos.

São variáveis fundamentais para o dimensionamento das estruturas das torres o tipo de solo, tipo de fundação, tensão de transmissão, angulação do traçado, geografia do terreno, necessidade de alteamento, capacidade de suporte de carga, altura de segurança cabo em relação ao solo, altura de segurança cabo e a vegetação, características de pressão de vento nas diferentes regiões.

Quanto a utilização de tecnologia que possibilite a utilização de faixa de segurança, cita-se um exemplo do empreendimento de grande porte para instalação da Linha de Transmissão Coletora Porto Velho - Araraquara 2, com extensão de $2.430 \mathrm{Km}$ partindo do 
Estado de Rondônia e passando por Mato Grosso, Goiás, Minas Gerais e São Paulo, cujo estudo detalhado foi objeto da tese de doutoramento de Ricardo Abranches Felix Cardoso Jr. ${ }^{19}$ Os projetos construtivos das linhas de transmissão, ao observarem alguns condicionantes adotados pelos próprios empreendedores ou pelos órgãos ambientais, como os do projeto citado determinados pelo Instituto Brasileiro do Meio Ambiente e dos Recursos Naturais Renováveis - IBAMA, nos estudos de impacto ambiental, possibilita a minimização dos impactos na propriedade agrária, observando particularidades de cada caso, características de fertilidade e produtividade do solo, culturas locais e execução de planos de manejo adequados.

Dentre as características associadas às linhas de transmissão, tem-se a opção por de estruturas (torres) autoportantes e altura que permite uma maior distância dos condutores (cabos) em relação às culturas que estão sob as linhas de transmissão.

Ressalta-se que o que se pretende com essa proposta não é a análise econômica dos impactos de tais medidas. Se por um lado representaria maior onerosidade às concessionárias quanto as adequações das redes, o que implicaria de forma reflexa em certo comprometimento da modicidade tarifária, por outro, os imóveis que passariam a ser afetado ao longo dos anos podem ampliar a produtividade de áreas cuja exploração é reduzida ou muitas vezes, integralmente suprimida.

Esse viés de produtividade das faixas de segurança não é a pratica usual das concessionárias. Considerando que o Brasil tem como característica um vasto território, esse aspecto pode não ser considerado como relevante na atualidade, mas dada a exigências de praticas de desenvolvimento sustentável pelas empresas, devem se tornar em alguns anos exigência de observância obrigatória.

Uma linha de transmissão, composta por condutores (fios) e estruturas que os sustentam (torres), possui vida útil regulatória definida pela Agência de Nacional de Energia Elétrica, que conforme Manual de Contabilidade do Setor Elétrico - MCSE, tem as taxas de depreciação divulgadas em Resolução específica daquela agência ${ }^{20}$.

Nos termos do Anexo da Resolução Normativa No 474/2012 da ANEEL, que estabeleceu taxas anuais de depreciação para os ativos em serviço outorgado no setor elétrico 
${ }^{19}$ CARDOSO JR., Ricardo Abranches Felix. Licenciamento Ambiental de sistemas de transmissão de energia elétrica no Brasil: Estudo de caso do sistema de transmissão do Madeira/ Ricardo Abranches Felix Cardoso Junior - Rio de Janeiro: UFRJ/COPPE, 2014.

20 ANEEL, Agência de Nacional de Energia Elétrica. Manual de Contabilidade do Setor Elétrico - MCSE. Brasília, 2015, p. 529. Disponível em: <http://www.aneel.gov.br/arquivos/PDF/MCSE__Revis\%C3\%A3o.pdf>. Acesso em 23/02/2015.

atualmente vigentes, a condutores de classe de tensão igual ou superior a $69 \mathrm{kV}$ e estrutura do tipo torre possuem uma vida útil de 37 (trinta e sete) anos. ${ }^{21}$

Considerando que esse prazo refere-se à vida útil regulatória, e que em regra os ativos de transmissão permanecem em operação por ainda muitos anos, visto sua essencialidade, o aprimoramento das condições de utilização se mostram cada vez mais indispensáveis que ocorram.

Por fim, a ABNT NBR 5.422 é a norma estabelece o valor de referência para exposição ocupacional corresponde a campos com densidades de corrente e fatores de segurança que devem ser observados pelas concessionárias e permissionárias de para o fornecimento de energia elétrica.

Conforme ensina Celso Fiorillo, a busca e a conquista de um ponto de equilíbrio entre o desenvolvimento social, o crescimento econômico e a utilização dos recursos naturais exigem um adequado planejamento territorial que tenha em conta os limites da sustentabilidade. O critério do desenvolvimento sustentável deve valer tanto para o território nacional na sua totalidade, áreas urbanas e rurais, como para a sociedade, para o povo, respeitadas as necessidades culturais e criativas do país. ${ }^{22}$

A Constituição Federal estabelece que a ordem econômica, fundada na livre iniciativa (sistema de produção capitalista) e na valorização do trabalho humano (limite ao capitalismo selvagem), deverá regrar-se pelos ditames de justiça social. Segundo Fiorillo, a ideia principal é assegurar a existência digna da pessoa humana, atreva de uma vida com qualidade.

O autor se volta para uma abordagem para o princípio da defesa do meio ambiente, contido no inciso VI do Art. 170, ressaltando que o mesmo não objetiva impedir o desenvolvimento econômico, mas exige-se que as atividades sejam desenvolvidas lançando-se mão dos instrumentos existentes adequados para a menor degradação possível. Não obstante, pode-se lançar mão do mesmo raciocínio para integração dos demais dispositivos constitucionais.

21 ANEEL, Agência de Nacional de Energia Elétrica. Resolução Normativa No 474/2012. Acesso em <http://www.aneel.gov.br/cedoc/aren2012474_2.pdf>. Acesso em 23/02/2015. 
${ }^{22}$ FIORILLO, Celso Antônio Pacheco. CURSO DE DIREITO AMBIENTAL BRASILEIRO. 14 ed. rev., apl. e atual. em face da Rio+20 e do novo Código Florestal - São Paulo: Saraiva, 2013, p. 79.

\section{CONCLUSÃO}

A energia elétrica, considerada essencial, repercute de inúmeras formas e em diversos setores, sejam eles ambientais, sociais, econômicos, geopolíticos, tecnológicos, enfim, requer uma agenda institucional, política e científica. Nesse sentido, a Política Energética brasileira se estruturou como política pública existentes, de forma a possibilitar a existência de infraestrutura necessária para sua implementação.

Deu-se enfoque à articulação do marco regulatório existente, realizando uma crítica quanto a sua organicidade e repercussão no planejamento da política energética, cujos impactos atingem as necessidades atuais e futuras. Verificou-se os aspectos referentes a investimentos mal planejados e subaproveitados, como aqueles necessários e deferidos.

$\mathrm{Na}$ análise do arcabouço normativo envolvendo eletricidade, a Constituição, conferiu competências material, legislativa e de outorga à União. No plano infraconstitucional, verificou-se a exploração, os direitos e deveres dos usuários e das empresas permissionárias ou concessionárias desses serviços públicos.

Realizou-se uma análise da essencialidade da energia elétrica com fator para o desenvolvimento social, demonstrando que segurança energética representa, de forma abrangente, segurança econômica, e a falta de acesso a esta por parte da população gera exclusão social a diminuição da qualidade de vida.

Considerando a eletricidade como um recurso econômico estratégico para o progresso e desenvolvimento do país, foram abordados temas referente à infraestrutura necessária para sua produção e distribuição, com ênfase à sua transmissão.

O sistema elétrico brasileiro podem ser agrupadas em quatro segmentos principais: Geração, Transmissão, Distribuição e Comercialização. Após breves digressões sobre tais seguimentos, e considerando os impactos decorrentes do seguimento de transmissão nos imóveis agrários, a transmissão passou a ser objeto de estudo mais detalhado. 
Constatou-se que o papel das Linhas de Transmissão, no plano teórico, é de assegurar o transporte da energia elétrica, atendendo tanto o suprimento da demanda por energia elétrica na sua forma mais eficiente, quanto do ponto de vista econômico e ambiental.

Para implantação de linhas de transmissão, consideram-se os fatores de localização, ambientais, interferências nos meios físico, biótico e meio socioeconômico, impactos ambientais decorrentes da implantação dos empreendimentos. Serão afetados também imóveis em grande parte situados e zonas rurais, que passarão a ter restrições no seu uso e gozo, afim de garantir segurança às instalações elétricas, assegurados pela legislação e os atos regulatórios infraconstitucionais que disciplinam essa matéria.

Apontou-se ainda as responsabilidades pelo Poder Público para a implantação e gestão das linhas de transmissão, a observância da intervenção aos particulares, gestão da segurança do sistema elétrico e do aproveitamento racional das áreas rurais afetadas.

O enfoque concentrou-se na gestão do uso das faixas de servidão pelos proprietários, os riscos e intervenções que as concessionárias ou permissionárias devem observar, como limpeza, efeitos dos campos eletromagnéticos nas intermediações das linhas de transmissão.

Por fim, demonstrou-se pontos de melhoria nos projetos de construção das linhas de transmissão, envolvendo desde traçado até adequações das estruturas, por exemplo, elevando sua altura para permitir a cultivo e produção na área reservada à faixa de segurança.

Feita menção da Linha de Transmissão Coletora Porto Velho - Araraquara 2, com extensão de $2.430 \mathrm{Km}$, passando pelos Estados de Rondônia, Mato Grosso, Goiás, Minas Gerais e São Paulo. O Instituto Brasileiro do Meio Ambiente e dos Recursos Naturais Renováveis - IBAMA, nos estudos de impacto ambiental, estabeleceu com as concessionárias medidas de mitigação dos efeitos decorrentes de implantação das obras.

Conclui-se, com este estudo, que devido à grande extensão do território brasileiro, não se verifica um planejamento que minimize as interferências das linhas de transmissão na propriedade agrária, como por exemplo, trajetos alternativos para sua construção ou o aumento da distância dos cabos em relação a solo.

Entretanto, a adoção de medidas de mitigação como a estudada demonstram que, estendidos para os futuros empreendimentos, representa benefício não só pelo aspecto de produtividade que beneficia o próprio imóvel agrário e a coletividade com o cumprimento 
da sua função social, mas também buscando deixar um legado às futuras gerações da preocupação com o desenvolvimento sustentável e com responsabilidade.

\section{REFERÊNCIAS}

ANEEL, Agência de Nacional de Energia Elétrica. Manual de Contabilidade do Setor Elétrico

- MCSE. Brasília, 2015, p. 529. Disponível em:

<http://www.aneel.gov.br/arquivos/PDF/MCSE_-_Revis\%C3\%A3o.pdf>. Acesso em 23/02/2015.

ANEEL, Agência de Nacional de Energia Elétrica. Resolução Normativa No 474/2012.

Acesso em <http://www.aneel.gov.br/cedoc/aren2012474_2.pdf>. Acesso em 23/02/2015.

BRASIL. Instituto Brasileiro de Geografia e Estatística - IBGE. Censo Demográfico 2010.

Disponível

em

http://biblioteca.ibge.gov.br/visualizacao/periodicos/93/cd_2010_caracteristicas_populacao_ d omicilios.pdf >.Acesso em 13-out-2014.

CARDOSO JR., Ricardo Abranches Felix Licenciamento Ambiental de sistemas de transmissão de energia elétrica no Brasil: Estudo de caso do sistema de transmissão do Madeira/ Ricardo Abranches Felix Cardoso Junior - Rio de Janeiro: UFRJ / COPPE / Programa de Planejamento Energético, 2014.

ELETROBRÁS. DEA. Avaliação de passivos ambientais: roteiros técnicos / Centrais Elétricas Brasileiras S.A., DEA; coordenado por Fani Baratz. - Rio de Janeiro : Eletrobrás, 2000.

FIORILLO, Celso Antônio Pacheco. CURSO DE DIREITO AMBIENTAL BRASILEIRO. 14 ed. rev., apl. e atual. em face da Rio+20 e do novo Código Florestal São Paulo: Saraiva, 2013.

FIQUEIREDO, Job de. A utilização do setor elétrico como instrumento de implementação de

políticas públicas. Rio de Janeiro, 2006 Disponível em: <http://www.nuca.ie.ufrj.br/gesel/eventos/seminariointernacional/2006/artigos/pdf/Job_Fi guei redo.pdf>. Acesso em: 22.jan.2015.

GRISI, Breno Machado. Glossário de Ecologia e Ciências Ambientais. $3^{\text {a }}$ ed. rev. e ampl. 
João Pessoa, 2007. Disponível em

<http://www.em.ufop.br/ceamb/petamb/cariboost_files/glossario_20de_20ecologia_20e_

20ciencias_20ambientais.pdf>. Acesso em 09-jan-2016.

LOUREIRO, Luiz Gustavo Kaercher. Algumas reflexões sobre a base normativa do setor elétrico brasileiro. Rio de Janeiro: IFE, 2007.

LOUREIRO, Luiz Gustavo Kaercher. Constituição, energia e setor elétrico. Porto Alegre:

Fabris, 2009.

LOUREIRO, Luiz Gustavo Kaercher. O regime jurídico da energia elétrica nas Constituições brasileiras - as premissas. In: REIS, Jorge Renato dos; LEAL, Rogério Gesta (Org.). Direitos sociais e políticas públicas: desafios contemporâneos. Santa Cruz do Sul: EDUNISC, 2008. Tomo 8.

MEDEIROS, Edmundo Emerson de. Infraestrutura energética: planejamento e regulação do setor elétrico. São Paulo : MP Ed., 2009.

PIRES, Adriano; FERNÁNDEZ, Eloi Fernández y; BUENO, Júlio Cesar Carmo (org.). Política energética para o Brasil: propostas para o crescimento sustentável. Nova Fronteira: Rio de Janeiro, 2006.

SAMEK, et al. A opção pela Hidrelétrica. Estado de São Paulo. 2007. Disponível em:

<http://www.estado.com.br/editoras>. Acesso em 16-jun-2014.

SANTOS, R. H. O Planejamento Integrado de Recursos e a Regulação: a experiência dos EUA e as perspectivas no Brasil. UPUSP/IEE, São Paulo, 1997. Dissertação (Mestrado) Escola Politécnica, Universidade de São Paulo. 